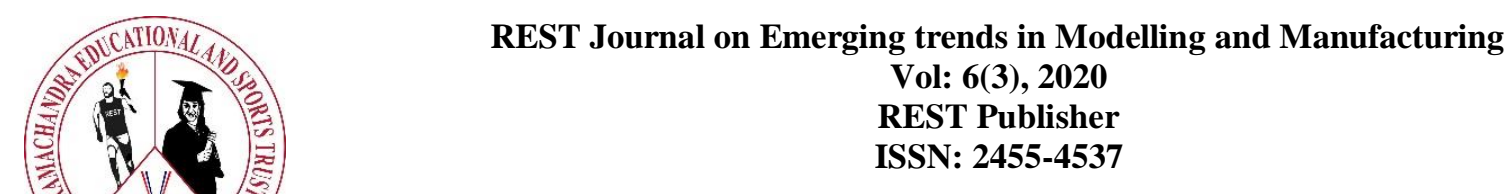

Website: www.restpublisher.com/journals/jemm

\title{
A Study on Group Technology Method Utilized in FMS
}

\author{
${ }^{1}$ Rushabh Podder, Karan Vaghela, ${ }^{2} \mathrm{M}$. Ramachandran \\ ${ }^{1}$ MPSTME, SVKM'S NMIMS University, Shirpur, Dhule, Maharashtra, India \\ ${ }^{2}$ REST Labs, Kaveripattinam, Krishnagiri, Tamil Nadu, India \\ sweetestchandran@gmail.com
}

\begin{abstract}
Group technology plays a vital role in neutralising many problems just by combining and grouping similar kind of problems and finding a single solution by reducing efforts and time. Part family is a family which contains similar kind of parts and similarly group of machineries producing similar parts is known as machine cell. Manufacturing of parts coming under a single family in a given cell or manufacturing line is known as cellular manufacturing. For cellular manufacturing, most important part is to form cells. Cell formation can lead to many problems like the kind of part to be manufactured and machines required for the same, also transporting the part accordingly whether it is intra-cell or inter-cell. Simulation being the virtual examination of the part that is to be manufactured, it becomes very easy to simulate the parts, its virtual process of manufacturing by reducing cost and material wastage with the accurate result we want. Similarly, as per the importance of the work, scheduling also plays important role by segregating the work according to its importance level and customer requirements. Using these techniques, we get into production section where actual work is produced. Production is also directly depending upon the flowchart that we use to reach the production line like from material selection $>$ algorithm $>$ coding > simulation $>$ manufacturing $>$ finished product. There occur many problems whenever going to start something new, even for group technology there occurred many issues and to solve it we used various algorithms such as Bees algorithm, clustering algorithm, genetic algorithm and many others. Therefore, by using mathematical equations related to the mentioned algorithms, many results have been found and issues have been cleared. Before manufacturing, it is necessary to distribute parts according to their part family and classification, so classifying is also a most important part in group technology where the parts are being classified according to their manufacturing date, code, and date engraved on the manufactured piece.
\end{abstract}

\section{Introduction}

Group technology is a technology in which, similar parts are being grouped and identified in order to carry out advantage of similar parts and their similarities during the process of designing and production. Hence it is the better way in which one can identify the parts accordingly. Cellular manufacturing is a process that fabricates families of parts within a single cell of machines operated by operators who work only within the cell. A cell is a small scale, vividly-defined fabricating unit within a factory. Cell formation present in group technology, five tooling is identified with operation types. Operation sequences would or would not precede constraints. In the model it's assumed that the construction base is determined by the operation type and parts split operations may share a setup. Each part type has a planning value. The cell formation problem is foremost procedure for designing the cellular manufacturing system. The most important objective of Cell Formation is to set up machine cells and part families, further deliver part families to machine cells and finalize the selected performance measures such as inter-cell and intra-cell travelling cost, group efficiency and exceptional elements. Simulation is a technique which helps in entering a virtual world for doing the same work which is to be done in real (actual world). Simulation helps in optimizing, testing, training as well as in educational purpose to study about a model. Hence, simulation used in group technology helps to attain the approximation and appropriate result required to build, or to simplify the design that is required in group technology. Scheduling, the process involves arranging, controlling as well as optimisation of the work as well as workloads present in the process of production and manufacturing. It is used to allocate machinery, planning human resources, planning processes included in production, and procuring materials depending on the needs. Scheduling being an important tool for both engineering as well as in manufacturing, it has a major impact over process related to productivity. Considering scheduling in the process of manufacturing, it helps in reducing costs by reducing production time, by listing down the work process according to their importance in manufacturing. Algorithm is the procedure/formula used to clear a problem, dependant on managing a sequence of specific action. A computer code could be focused as elaborated algorithm. In maths and CS, algorithm basically means a minute process which provides a solution for a repeated problem. Production, a process of combining various material inputs and immaterial inputs in order to make something consumable. It is the process 
of manufacturing output, a good or service which contains value and contributes to the utility of ones' individual. The area of economics that puts light on production is known to as production theory, which in many respects is similar to the consumption theory. Manufacturing is the fabrication of products for utilization or sale, using labours and machineries, tools, chemical or biological processing or formulation. It is the extract of secondary industry. The term is usually used to industrial design, in which raw materials from primary industry are altered into finished goods on a large scale. The planning, scheduling, and performing of a program. 2a: the process of instructing or learning by means of an instructional program. b: the process of preparing an instructional program for a device (such as a computer). Group technology is drawing increasing interest from manufacturers because of its many applications for boosting productivity. GT is an approach to manufacturing that seeks to maximize production efficiencies by grouping similar and recurring problems or tasks. Neural network, a circuit consisting of neurons, or a circuit consisting of artificial neurons/ nodes, known to be artificial neural networks. It can be biological neural network consisting of actual biological neurons or, to solve artificial intelligence problems, artificial neural networks are used. In group technology, use of neural network is (artificial neural networks). As it helps in solving machinery/ connection problems that take place while arranging machineries involved in grouping and forming cells. The acceptable range of output is generally between 0 and 1 or could range between -1 and 1 . The object-by-object collation of two or more comparable processes, alternatives, qualifications, products, sets of data, systems. Taking into account, for example, changes in a financial statements item over several calculation order may be presented together to recognize the emerging trends in the company's operations as well as results. A relational database is a database that stocks and gives permission to data points that are related to one another. Relational databases are built on the relational model, an inherent, direct way to represent data in form of tables. In this kind of database, each row in the table is a record with a special ID called the pass-key. Conceptual model is representation of a system, made of composition of concepts which are utilised to help people know, understand, or simulate a subject the model depicts. It's also a set of concepts. In contrast, physical models are physically placed items. A database abstraction is a simplified depiction of a database in the form of a written scripture or a diagram. Abstraction is the process of removing characteristics from something in order to deduct it to a set of essential characteristics. Coding refers to creating computer programming code. In a more general sense, the word coding is used to refer to assigning a code or classification to something. It is the process of organizing jobs or products into particular groups based on their type. As it helps in classifying the jobs and products required for the kind of work, and as per its uses for which it is manufactured. Resource allocation is a process which supports the company goals by managing authorities and assets in a result-driven manner to achieve strategic goals. Grouping together of linked operations according to the product flow. In a cell, machines are generally laid out in a sequence to permit single-piece flow without queuing or intervention. Also termed as cell layout, it differences with functional layout. Clique over or clique partition according to graphical theory, is clique of a given to an undirected graphical partition of vertices of a graph into cliques, the subsets of vertices in which every 2 vertices are adjacent to each other. Minimum clique partition is a partition which are used as few cliques possible. Tabu search is a metaheuristic searching method using local methods used for mathematical optimization. Local (neighbourhood) searches provide a potential/better solution to a problem and check its immediate partners/side-byes (that is, solutions that are similar except for very few minor details) in the hope of finding an improved/better result for optimising the situation mathematically. Shipbuilding is the process involving construction of ships and other floating vessels. It generally is manufactured in ship yards. Reason behind Involving ship building in group technology is, the manufacturing process applied in ship building is as similar to that of cellular manufacturing. Ship building and ship repairing, both military as well as commercial are referred as naval engineering. A method of imaginary listing the steps involved to carry out a particular business procedure. A type of process flow popular amongst business empires might take the form of flow charts that displays inputs or information requests, followed by each of the steps required to generate required outputs such as products or services from the provided inputs. An interactive activation and competition network (hereafter, IAC network) consists of a collection of processing units organized into some number of competitive pools. There are excitatory connections among units in different pools and inhibitory connections among units within the same pool. Part family formation gives a number of benefits in terms of manufacturing, processing, designing and purchasing. All parts in a given family, depends on the purpose, requires similar treatment, carrying and design features, enabling reduced setup times, improvement in scheduling, improvement in process control and standard process plans. Combinatorial optimization is the part that contains finding a precise object from a countable set of items. In many such problems, exhaustive search is not tractable. The Grouping Genetic Algorithms were developed to decode clustering issues. It is a genetic framework used to group problems, i.e. each particular problem needs its own modification. As the name recommends, GGA is an implementation of the conventional Genetic Algorithms adapted to grouping problems. Genetic issue/ genetic disorder is a health problem related to abnormalities related to genome. It can be caused by mutation that is monogenic or polygenic or could be by chromosomal tweaks. Similarly, in group technology and cellular manufacturing, this can be a big issue. Hence, to reduce genetic issue, various algorithms are being used. Adaptive resonance theory is prospered by Stephen Grossberg and Gail Carpenter on the concept of how our brain processes information. It elaborates on various neural network models which uses supervised and unsupervised learning methods, and remits problems such as pattern recognition and prediction. Pareto-optimality, a concept of efficiency used in the social 
sciences, including economics and political science, named for the Italian sociologist Vilfredo Pareto. The incident of varying in different conditions: Price subjected to variation. an instance of this: There is an alteration in the quality of material delivered via shipment. an instance of varying or the amount, rate, or degree of such change. Clothing industry shortens the type of business \& industrial aspect with the manufacturing and life cycle of cloth and inner wears, emphasising on the textile companies (manufacturers of cotton, wool, fur, and synthetic fibre), adornment using embroidery, by the fashion industry to vogue retailers up to trade with second-hand cloth and textile recycling. Automatic generation of plan assembly is a level of assembly process planning in which a task plan is initiated directly from a model of the suggested assembly. This not only includes the generation of a series of operations to build the assembly but also the design of an accurate workspace with satisfactory fixtures and tools. Understanding a Product Family. The individual products in a product family are often quite similar. Their composition, packaging, and pricing may be nearly but not quite identical. Concurrent engineering is the methodology emphasizing tasks to work parallel, it is sometimes also called as simultaneous engineering or integrated product development using an integrated product approach. A hierarchical classification is a classification that maps input data into required output categories. The classification occurs first on a low-level with highly specific species of given input data. "Numeri's" redirects here. For the field of computer science, see Numerical analysis. Numerical control (also computer numerical control, and commonly called CNC) is the automated control of machining tools (drills, boring tools, lathes) and 3D printers by means of a computer. Batching definition, a quantity or number coming at one time or taken together: a batch of prisoners.

\section{Inside Information}

The motive of this paper is to display the common base of various database design modelling principles as distinguished with the modelling principles applied in group technology. An implementation of group technology retrieval scheme applying a relational database management system [2]. The ideology of Group technology is to stack a manufacturing process so that it gets fit into a manufacturing system such that it could be easily perish into readily managed sub-system [12]. The given paper consists of a different method used for group formation according to group technology using part encrypting as well as stratification. The major machine part categorising problem uses the product flow analysis concept, which a machine is assigned to a non-descriptive weight [17]. We get to know about a single machine scheduling problem, the scheduling supervisor determines the due date for other jobs in a group technology society. In group technology society, the bifurcation of the job into family is provided and jobs of the same family is required to be made consecutively. The separation of the job into family is done to gain efficiency for high volume production by deploying similarities of different products and activities present in the production [21]. In the written paper we provide a congested view of the literature for cell formation aspects to design cellular manufacturing system. The uses and flaws of existing approaches are known here [22]. The paper shows clique partition for Group Technology problem. The new ideology is established on a basic quadratic programming formulation, also addressing various objectives in GT problems by taking on production relationship to allot varying weights to part pairs [26]. To include lean process flows in ship manufacturing, the main concept of group technology is used. When group technology concepts are used and combined, it forms effective process lines, lean ship production would be realized [27]. Proper focus is kept for improvising the efficiency of a precise collection manufacturing systems. Small collection manufacturing has carried inside a job shop territory, uses process layout. Experience shows that this isn't an ideal case for territory in which order is characterized by repeated demands for a given set of parts/objects. High frequency decreases quality of capacity, heights delays, and includes huge batch size. An alternative path has been involved the cellular manufacturing principles of Group Technology [30]. Cellular manufacturing is an applied version of group technology, it is a fabricating principle based on the approximations that a higher level of efficiency and integration could have been achieved by clubbing similar families and similar machines together. To be specific, cellular manufacturing, an ideology of clubbing different machines together and letting the machines to the production of one or more part families which share ordinary building requirements [32]. Group technology (GT) is a manufacturing philosophy that attempts to reduce production cost by reducing the material handling and transportation cost. The GT cell formation by any known algorithm/heuristics results in much inter-cell movement known as exceptional elements [35]. The review paper discusses about stacked procedure for levelling less amount and high mix production obliged on the basis of Group Technology. The procedure is taken from the standard levelling approach applied in huge production. It uses clustering technique to start the large number of product varieties into a manageable number for product families. These families are used to constitute a family-oriented levelling pattern. Focusing on the clustering process, hence the paper elaborates about grouping criteria that could be chosen and how product families can be bifurcated for levelling [39]. Group Technology applications are limited to the actual production activities. Parts that require similar manufacturing process were grouped together and process consecutively in order to reduce the amount of set-up changes and work-in-process inventories, and to increase throughout the rates. However, the implementations of Group Technology have expanded to other fabricating activities, such as part design, variant process planning, manufacturing cell design, facility layout \& scheduling. The Group Technology concept has been a main path towards a higher level of computer-integrated manufacturing [41]. Group technology is one of the manufacturing philosophy having the idea is to focus on similar activities. This is philosophy which has a broad applicability, potentially influencing all areas of production organization. One specific application of group technology is cellular manufacturing system, which includes processing collections of related parts on devoted group of different machines or manufacturing process for shooting up the productivity [42]. The adaptation of GT philosophical principles and then implementing of cellular manufacturing 
layout and operational control concept together constitutes one of the most significant advancements in the source for faster, better, cheaper production and delivery of finished manufactured goods over past 50 years. Designing effective cells involves finding similarities in product design and process plans between products as well as the components. In doing so, the production engineers have succeeded in obtaining the efficiency of product layout, controlling the simplicity of small systems as well as the flexibility of process layouts across a broad spectrum of manufacturing environment. Cellular Manufacturing systems consist of one or more than one manufacturing cells [43]. A disadvantage of Group Technology established cellular manufacturing systems is that they have limited flexibility offsets that setup, also material handling effectiveness they provide. Virtual Cellular Manufacturing system does not face this problem of limited tracking flexibility, but do not give out the same effectiveness that Group Technology based cellular system gives. Therefore, the study differentiates the performance of a Group technology based cellular manufacturing system that uses operation overlapping, to further improve material flow efficiency with virtual cellular manufacturing system [44]. This is the first research in its kind that applied the concept of group technology to improve performance of small and micro enterprises that produce cultural clothing. The current small and micro enterprises that produce cultural clothing are applying an informal grouping technique. Because of this, they spend too much time to design, set price, explain the property of the product to customers, and retrieve an already designed parts. In order to investigate this fact, samples of 111 small and micro enterprises that produce cultural clothes around Gulele sub-city were studied [46]. To neutralise the production, a result is to classify products into class, on the basis of similarity required for manufacturing the product. The technique known as group technology help us to reduce the nonrequired products in a production unit by making modellers aware of existence of similar component. In this paper a new method is shown and it provides allowance to classify the manufacturing sequences as well as tree-like manufacturing plans [50]. Traditional group technology (GT) or cellular manufacturing is limited to two dimensions being part and machine. In a factory layout or a production process, the factors affecting GT are not only parts and machines, but also the operator, carrier, manager, etc. Reports are seldom written about multi-dimensional GT. In this research, a new algorithm to solve multidimensional GT problems is offered. The significance of this algorithm is to arrange all incidence matrices as a single incidence matrix that is symmetrical and can point out the sorted groups directly [51]. Group Technology is a vast concept which uses common attributes to reduce redundant work in designing and manufacturing, then results in shorter product development and production time. This feature shortens product development and production time also provides a significant advantage for manufacturers by making them to respond faster to market demand/changes and run production more economically in now-a-days highly competitive manufacturing environment [52]. This paper studies the problem of scheduling jobs in a two-machine open shop to minimize the make span. Jobs are grouped into batches and are processed without pre-emption. A batch setup time on each machine is required before the first job is processed, and when a machine switches from processing a job in some batch to a job of another batch. For this NP-hard problem, we propose a linear-time heuristic algorithm that creates a group technology schedule, in which no batch is split into sub-batches. We demonstrate that our heuristic is a (5/4)-approximation algorithm. Moreover, we show that no group technology algorithm can guarantee a worst-case performance ratio less than (5/4) [53]. Reports are seldom written about multi-dimensional GT. In this research, a new algorithm to solve multi-dimensional GT problems is offered. The significance of this algorithm is to arrange all incidence matrices as a single incidence matrix that is symmetrical and can point out the sorted groups directly [51, multidimensional group technology].

\section{Cellular Manufacturing}

Cellular Manufacturing system consists of one or more than one cells for manufacturing. Ideally, every cell contains the necessary resource and authority to build a specific set of part types or products to reach appropriate production plans. These cells typically have influenced resources allocated in a meaningful, contiguous as well as physical footprints. This combines employees, machineries \& required tools for manufacturing. The independent chamber team takes all the required responsibilities for scheduling, maintaining the production, quality assurance, as well as for production. In some cases, condition would be like, the cells be virtual in nature \& allowing for frequently reallocation as demand and product list changes. Such cells would be still being operated to maintain set-up, flow and production control advantage [43]. A cellular manufacturing system is a desired output of group technology principle for manufacturing products. It involves groups of similar components in a focused cluster of unknown series of machines. In the following paper, the steps that form the cluster balancing on the processing time that is suggested. For even distribution of workload, workload balancing is carried out in the other part phase of the model, i.e., a time-dependant model. The time-dependant model is compared with the workloaddependant model using a commonality score [42]. Cellular manufacturing is an industry based application of group technology. One of the problems faced in implementing the Cellular Manufacturing is the cell formation problem. The CFP used here is to group machines and parts in dedicating manufacturing cells so, the number of errors and exceptional elements in cells are deduced [29]. Cellular manufacturing (CM) is an implementation for group technology in a manufacturing system. It is based on employees who are processing part families, or collections of similar parts, in cells, or clusters of dedicated machines that may be different in function. The justification of cell formation includes reduction in setup time, work inprocess inventory, cycle time, tooling requirements and material handling. Other than this, CM implementation has achieved significant improvements in product quality, scheduling, space utilization, control of operations and raising employee morale. An important requirement for CM is not only an increased level of technical skills, but also the flexibility of workers, coupled with the ability to work together in a team [38]. The cell formation problem is one of the main problems in the design of Cellular Manufacturing. In several previous years, many solution methods are being developed for solving Cell Formation Problem. A detailed review of the present researches and solution approaches for cell formation problem can be found in this 
paper [29]. Cellular manufacturing has gained increase in attention since few years. The main problem in sketching cellular manufacturing systems is formation of cells as it is related to grouping parts with similar processing requirements into part families and machineries indulged in machine cell. The paper puts forth a kind idea for solving the problem related to cell formation [33]. Cellular manufacturing (CM) is an important application of group technology (GT) in which families of parts are produced in manufacturing cells or in a group of various machines. Cell design/formation is the first step in the design of cellular manufacturing systems [40]. In fractional cell formation, the materials in a part family pass inside its linked GT machine cell, and moves through another GT reminder cell. The flow between a GT cell and reminder cell is not known as an exceptional element; but the flow within GT cells would be accepted as exceptional elements [35, fractional cell formation]. A machine-part matrix for incidence taken place, cell forming task includes the shuffling of rows and columns of given matrix to create machine cells with regards to part families. In the research we try to determine a rearrangement so that the inter-cellular movement can be reduced and the utilization of the machines within a cell can be increased [34]. In group technology/ cellular manufacturing, machines and parts of a system are communicating. To height the effectiveness of the system, a cell forming problem is dismissed in order to distribute the system into other small systems that are as automatic as possible in the sense that the communication of the machine and the section within a sub-system are increased and that the link between machines and parts of other sub-systems are made less as possible. This gives opportunity to reduce the cell formation problem [49]. Simulation was established using multiple retakes, considering initialization bias, batch independency, observations normality, and decreasing variations. The period of initialization was the determination and hard work of Scrubbed, Singh, and Tierney using their own method. Batch sizes were set using computers and programming to meet requirements of normality and independency [30]. The study used simulation to check the performance of the different cellular manufacturing implementations, a virtual cellular manufacturing system and a group technology-based cellular manufacturing system, under the condition that are likely to affect their performance. Virtual Cellular Manufacturing has eight-department, 30-machine shop. Each department has either three or four look alike machines for performing similar works [44]. Single machine scheduling: Single machine scheduling problem is one in which the scheduler is determining the due dates for multiple jobs in a group technology nature. In group technology nature, a bifurcation of the jobs into group is provided and jobs of the same family are required to be processed one after the another [21].

\section{Algorithm}

Clustering Algorithm: The cluster identification algorithm effectively gives the solution of the standard Group Technology problem under the assumption that the machine-part matrix for the performed incidents indulges into mutually distributable sub-matrix. This do not occur very often in practice. Hence, the cost analysis algorithm is developed. This algorithm is the extended version of the cluster identification algorithm [12]. Genetic Algorithm: Genetic Algorithm is the newly optimized approach which try to copy natural process in order to re-assemble general purpose optimization procedures. Genetic Algorithm, researched by Holland, was used extremely as a bypass method for clearing different optimization problem in a huge number of application domain which included engineering, biology, economics, agriculture, business, telecommunications, and manufacturing. As a general-purpose research method, Genetic Algorithm club together element of directed and stochastic searches used to explore and exploit the search space to gain good results. With respect to other stochastic research processes, genetic algorithms have few unique features: implicit parallelism, population-based search, independence of gradient information, and flexibility to hybridize with domain dependent heuristics. These features most probably makes Genetic Algorithms a preferred choice other than traditional heuristics [29]. Bees Algorithm: Cell Formation algorithm uses the ability of the Bees Algorithm to find the accurate slots allotted to part families and machine cells such that the bond energy metric $\alpha$ is increased [33]. Differential Evolution Algorithm: The section here describes how Differential Evolution meta-heuristic is modified to solve the cell formation problem which is discrete in nature. The original Differential Evolution algorithm could only optimize problems in which the elements of the solution are continuous real numbers. Therefore, several approaches had been used to deal with discrete optimization by Differential Evolution. Most of them rounded off the variable to the nearest available values before evaluating each trial vector. In the following subsections we introduce a new Differential Evolution algorithm technique based on the structure of the Multi Phase Cell Formation problem. The new algorithm called Group Differential Evolution is a mutation equation analogous to the classical Differential Evolution's mutation which enables us to maintain all major characteristics of Differential Evolution [34]. Production levelling: The focus of production levelling is to weigh production rate as well as production mix by detaching production orders and customer requirement. In contrary to large scale production, levelling keeps production volume and mix equal and less time consuming. The sequence of this slot defines a timely based manufacturing accuracy, in essence to a repetitive pattern. According to this levelling pattern, every product type is produced within a timely basis [39]. Production Planning: Usability of conventional levelling techniques in a manufacturing unit is congested by the respective product diversity. Hence, levelling has obviously demanded in huge amount production. It could be used in lesser amount and high mix production by means of an adapted levelling traces. This used track uses clubbing technique to group product types into families. After that, a family-based levelling pattern is generated [39].

\section{Manufacturing}


Lean Manufacturing: As the world has started to move towards a world economy, clash within the manufacturing companies also have risen and reached world-wide. The increasing competitive nature has also led to intensive thinking for the units that are on the top in terms of competition. Hence, the concept of lean manufacturing has emerged. It provides steps required to move the manufacturing unit much closer to lean manufacturing in terms of flow, and gives a solution by which it determines how near it is to imaginary flow of ship-building system [27]. Researchers throughout the world have put forth various calculations and theories related to Lean Manufacturing, it works as a manual and gives path to lean manufacturing workers. A review of these theories revealed that they get affected from various flaws and drawbacks [45]. Cell Manufacturing: In this paper we provide a concise review of the literature on cell formation aspects of design of cellular manufacturing systems. The usefulness and limitations of existing approaches are identified. Future research directions are explored considering manufacturing requirements [22]. Parametric Part Programming: It is myth, group technology is one of the trackable path followed to reduce similarities and source of that impact. One of the minimum timely used feature of CNC technology said to be as parametric part programming in the maintenance of common solution feature of group technology in the process a set of identical parts [52]. Many of the researchers have found the literature follow production flow analysed data \& try to separate part and machine in such a way that it affects performance criterion such as grouping efficiency, grouping efficacy, group technology efficiency [29]. Few of the researchers have described a latest model for cell formation in cellular manufacturing system, based on cell usability concept. The work of that model is to decrease the number of errors in cells to achieve higher performance of cell usability [29]. Scientists tested the application of Lean Manufacturing in a mining area. They ensured the implementation of certain Lean Manufacturing elements which are applicable in this unit and noted that health and safety-related incidents had decreased from 154 to 67 [45]. Relational database is the Structured Query Language (SQL) relational database management system, the Interactive System Productivity Facility (panel display), the REXX programming language, and the REXX/Structured Query Language (RXSQL) interface [2]. Coding shows a different methodology of group formation in group technology using part identification. The major number of machine to part clubbing issues use the product flow analysis, it is the concept in which, a machine unit is given data of non-descriptive weight of the part [17]. DCLASS coding system is adopted and customized to classify and code parts of the cultural clothing. A database is developed to store the designs of these parts and use it for retrieval in the future. Future researchers can classify and code other textile products and they can develop another classifying and coding technique that represents the parts more than DCLASS coding does [46]. The paper discussed about the problem that how to make component groups using part code and classification analysis. Because of the weighing effect, a more reliable meaning of similarity has been used to change the part-attribute into a similar coefficient to hand over a single measurement of the degree of identically between any components [17]. Products exported to foreign countries often gets indulged to local regulations, needs labelling in various dialects, or are changed to meet various electric and other infra-modular standard levels. In some situations, the real life use of the family due date assignment method may evolve for managing few grants rather from technical exemptions [21]. The review discusses a new clique partitioning model for the Group Technology problem. The new model, based on a quadratic programming formulation, addressing multiple objectives in Group Technology problems by focusing on production relationships to assign differing weight blocks to machine/ part pairs [26]. The review shows a Pareto-optimality-based tabu search algorithm to the machine-part combining issues with different objectives: reducing the amount of inter-cell and intracell moves and reducing the total cell load variation. A new path is followed to classify the non-encouraged results developed by the tabu search [40].

\section{Ship Building}

In most of the scenes, a ship is manufactured to a given order and customized to the specific details provided by the person who would buy it. The entire process of shipbuilding includes number of specific stages, including:

1.development of purchaser's requirements;

2.conceptual design;

3.blueprint design;

4.bidding/auctioning;

5.details of design and planning;

6.construction (manufacturing);

water trials and delivery. [27]. Process flows in ship manufacturing in most situations is, a ship is produced according to the order and modified to the specific requirements of the purchasing person. The whole process of ship manufacturing includes a various specific stages [27]. The part that acquires a group of machines which are identical, forms a part family: the machines that are used to fabricate certain part families form a group of machine. Hence, the path travelling time of a part along various machines can be decreased and the changes for machines could be decreased. The part-machine familyformation problem is, hence, explained as one of most assigned part into family and machines onto groups according to the necessities [32]. The focus of cellular manufacturing in areas is a very well-known manufacturing philosophy that initially improvise manufacturing efficiency by focusing on the technique of group technology. It is important that, for the accurate and $100 \%$ usage of cellular manufacturing, one has to focus at both technical related drawbacks (cell formation and design) as well as human disabilities [38]. It is a perspective to solve the cell formation problem when there used to be objectives 
creating conflicts. The objectives were: increasing the machine usage, depleting the sum of extra machines, and decreasing the amount of exceptional elements [40]. This research mainly focuses on proposing an appropriate classification and coding system for Ethiopian cultural clothing. Previous research has been conducted and a suitable classification and coding system was recommended by different researchers. And this is the first research in its kind that applied the concept of group technology to improve performance of small and micro enterprises that produce cultural clothing. The current small and micro enterprises that produce cultural clothing are applying an informal grouping technique. Because of this, they spend too much time to design, set price, explain the property of the product to customers, and retrieve an already designed parts [46]. In this concurrent engineering path, the problem based on product building are taken into consideration, possible in designing process. Manufacturing and assembly process design are of very high expenditure, clearing all the further steps of industrialisation and development. This method is generated for new world fabrication surroundings that are substantially maintained in product families with variety of variants and options. Encountering the bottle-neck issue, the access allows an actual picture of assembly sequence allowing generation of a reduced steps of non-redundant assembly plans called metasequences [50]. In concurrent engineering, there are problems taken into account related to fabricating products as readily as possible in designing process. As fabrication and assembling process design are costly, process includes all the further steps of industrial process and fabrication. Here, a system for assembly plan generation, based on the concept of meta-product, is shown [50]. Algorithm proposed, is used to calculate the gap between sequence. Destruction, insertion and substitution operation has a worth. The simultaneous distance matrix is used for the categorisation tree. Using the bottom-up hierarchical classification algorithm, the dendrogram is generated [50]. The study focuses on the application of the Group Technology concept to a specific requirement of computer-aided manufacturing, that is, NC coding of machining and turning centres. The basic steps for these types of issues of GT and the parametric programming capability of computer numerical control (CNC) machines are used to create a single NC code for each and every part family. For CNC machine operators, the combination of parametric programming is expected to make an opportunity to generate NC codes and operate CNC machines with much more accuracy [52]. The problem of scheming jobs in a two-machine open shop to reduce the make-span. Jobs are clubbed into batches and are manufactured without pre-emption. A batch setup time on each machine is necessary before the first job is made, and when a machine switches from processing a job in one batch to another batch. For this reason, we put a linear-time heuristic algorithm that makes a group technology scheme, in which no batch is split into sub-batches [53]. We here focus on two-machine open shop scheduling issue with batch setup times. This issue is an upgradation of the traditional version of the two-machine open shop issue without batching, it is one of the heavy multi-stage model in scheduling theory [53].

\section{Conclusion}

The study focuses towards the need for generating the manufacturing system for most suitable activity to be performed and how Group Technology is still the spine of every manufacturing system present in any establishment. By applying cellular manufacturing to this plant the average WT, ST \& FT were reduced by $41 \%, 59 \%$ \& $30 \%$ respectively. Cost associated with this venture is considerably small in comparison to benefit derived. Cell formation helps the user to divide the work according to the different cells and importance. Hence cell formation has made it easier to work in the modern manufacturing system. By applying the 1) part family identification, 2) machine group identification, 3) part family/machine grouping simultaneously, these methods we have overcome the problem of cell formation. Simulation is used during pre and post stages of the designing cycle to provide solution for critical designing queries, combining those gathered during processing. Pre use of simulation is initially beneficiary in cases where it can be used on a repetitive basis throughout the design procedure. Scheduling is a part of modelling and simulation, where it is a process of arranging, controlling and optimising workloads in a production process. By scheduling the work as per importance, it helped to complete the work as per timely basis. Hence by applying the algorithms (Bees, genetic, clustering, differential evolution) we have reduced many complexities involved in group technology, most importantly cell formation, part identification as well as machine grouping. The assumptions and principles of levelled production were adopted not on the basis of any known studies but as a result of the authors' own experience and logical approach to the problem solution. Production planning is an inseparable part of every product's implementation. It allows for safe product development as it helps to measure possible threats and risks. Hence by applying product levelling, product planning, following Toyota production system and production rationalisation has led to higher profits and selection of the products giving higher profit to the company. Programming has become the most important aspect for industries working under automatic operated machines such as CNC lathe, CNC milling, VMC's, robotic arms etc., to apply group technology in the industry. Group efficacy has the potential to affect a group's mission and commitment, the manner in which group members work together, and the group's resilience in the face of difficulties

Group efficacy has the potential to affect a group's mission and commitment, the manner in which group members work together, and the group's resilience in the face of difficulties. Group efficacy has the potential to affect a group's mission and commitment, the manner in which group members work together, and the group's resilience in the face of difficulties Mathematical model is a simulator and calculation based results that has helped us to reach the required result for the research. In optimization problems the objective is to minimize the numbers of bottleneck machine while constrains have to be considered. Hence, using artificial neural networks we have minimised many bottlenecks under group technology. Comparative analysis is the basis in which we compare various methods that are used to optimise and measure the differences 
and choose the best fit optimisation technique for the research. Hence, it gave the most important aspect to select the best fit technique for group technology. By coding, one can easily reach the final product required. So, using codes in group technology makes it easier to follow more than one system for producing a same product in a group. Classification is the arrangement of items into groups according to some principle or system where similar items are grouped together based on their similarities, and separated by their specific differences. Hence, classification of components is very much important while grouping the similar components. To find clique partitioning problems we stepped by showcasing new grade of surfacedefining disproportions and by giving list of steps that builds surface-defining disproportions. At the end, we affirmed that some of the disproportions described help in boosting lower boundaries when operating a basic cutting plane algorithm on real-life instances. The word tabu comes from the Tongan word which indicates things that can't be touched because they are precious/sacred. Tabu search is a metaheuristic algorithm that can be utilized for solving combinatorial optimization problems. So by using this metaheuristic algorithm, we found solution for the related problems of forming cells. Part family formation is done to separate the parts belonging to same family and part family evolution in group technology has been a boon as it helps in identifying and manufacturing same type of parts belonging to same family. The result shows that the model for true dispense of workload provides better claims than the workload based model. The minimum amount of workload deflection and deflection index indicates the better performance of the cell formation procedure. Ethiopian culture clothing can be a good example for knowing group technology as it has divided the clothing style with the number of communities on the basis of their clothing style. In group technology, product family has made it easier to differentiate products as per their specifications, coding and requirement. So, creating product family has made it easier for the companies to locate as well as allocate the products according to their family. Concurrent engineering or simultaneous engineering used in group technology has helped to do more than one work simultaneously at same time. It has helped the company to generate multiple parts simultaneously and complete the work by reducing the problem of material storage. Computer Numeric control is a machining process that uses computer to manufacturer product according to the program fed in the machine. CNC machining offers a fine solution for rapid manufacturing of parts. The current scenario is using an index able tool, managed to eliminate multi set-up for the work piece. The visibility programme is an effective method to identify the orientation for finishing operations.

\section{References}

[1].Billo, Richard E., Rob Rucker, and Dan L. Shunk. "Enhancing group technology modeling with database abstractions." Journal of Manufacturing Systems 7, no. 2 (1988): 95-106.

[2].Kusiak, Andrew, and Wing S. Chow. "Efficient solving of the group technology problem." Journal of manufacturing systems 6, no. 2 (1987): 117-124.

[3].Offodile, O. Felix. "Application of similarity coefficient method to parts coding and classification analysis in group technology." Journal of manufacturing systems 10, no. 6 (1991): 442-448.

[4].Shabtay, Dvir, Yisrael Itskovich, Liron Yedidsion, and Daniel Oron. "Optimal due date assignment and resource allocation in a group technology scheduling environment." Computers \& Operations Research 37, no. 12 (2010): $2218-2228$. [5].Mehul Nautiyal, Aditya Shrinet, Ramachandran M, Mechanical, Thermal and Morphological Characterization of Basalt Fibre Composite- A Review IOP Conference Series: Material Science and Engineering, 810 (2020) 012043.

[6].Singh, N. "Design of cellular manufacturing systems: an invited review." European journal of operational research 69 , no. 3 (1993): 284-291.

[7].Wang, Haibo, Bahram Alidaee, Fred Glover, and Gary Kochenberger. "Solving group technology problems via clique partitioning." International Journal of Flexible Manufacturing Systems 18, no. 2 (2006): 77-97.

[8].HUDSON, M., J. LEAN, and P. SMART. "Production Planning \& Control: The Management." PRODUCTION PLANNING \& CONTROL 12, no. 8 (2001): 804-813.

[9].Mahdavi, Iraj, Mohammad Mahdi Paydar, Maghsud Solimanpur, and Armaghan Heidarzade. "Genetic algorithm approach for solving a cell formation problem in cellular manufacturing." Expert Systems with Applications 36, no. 3 (2009): 6598-6604.

[10].Moon, Y. B. "Forming part-machine families for cellular manufacturing: A neural-network approach." The International Journal of Advanced Manufacturing Technology 5, no. 4 (1990): 278-291.

[11].Pham, Duc Truong, Ashraf Afify, and Ebubekir Koc. "Manufacturing cell formation using the Bees Algorithm." In Innovative Production Machines and Systems Virtual Conference, Cardiff, UK. 2007.

[12].Noktehdan, Azadeh, Behrooz Karimi, and Ali Husseinzadeh Kashan. "A differential evolution algorithm for the manufacturing cell formation problem using group based operators." Expert Systems with Applications 37 , no. 7 (2010): $4822-4829$. 
[13].Bidanda, Bopaya, Poonsiri Ariyawongrat, Kim LaScola Needy, Bryan A. Norman, and Wipawee Tharmmaphornphilas. "Human related issues in manufacturing cell design, implementation, and operation: a review and survey." Computers \& Industrial Engineering 48, no. 3 (2005): 507-523.

[14].Pramod Raichurkar, M. Ramachandran, V. Subramanium, The structural and mechanical properties of the crepe-de chine fabrics material, International Journal of Mechanical and Production Engineering Research and Development, 2018, December, 103-108.

[15].Bohnen, Fabian, Thomas Maschek, and Jochen Deuse. "Leveling of low volume and high mix production based on a Group Technology approach." CIRP Journal of Manufacturing Science and Technology 4, no. 3 (2011): 247-251.

[16].Lei, Deming, and Zhiming Wu. "Tabu search for multiple-criteria manufacturing cell design." The International Journal of Advanced Manufacturing Technology 28, no. 9-10 (2006): 950-956.

[17].Moon, Y. B., and U. Roy. "Learning group-technology part families from solid models by parallel distributed processing." The International Journal of Advanced Manufacturing Technology 7, no. 2 (1992): 109-118.

[18].Angra, Surjit, Rakesh Sehgal, and Z. Samsudeen Noori. "Cellular manufacturing - A time-based analysis to the layout problem." International Journal of Production Economics 112, no. 1 (2008): 427-438.

[19].Askin, Ronald G. "Contributions to the design and analysis of cellular manufacturing systems." International Journal of Production Research 51, no. 23-24 (2013): 6778-6787.

[20].Kannan, Vijay R. "Analysing the trade-off between efficiency and flexibility in cellular manufacturing systems." Production Planning \& Control 9, no. 6 (1998): 572-579.

[21].Anand, G., and Rambabu Kodali. "Development of a framework for lean manufacturing systems." International Journal of Services and Operations Management 5, no. 5 (2009): 687-716.

[22].Nesibu, Bethlehem. "Part Family Formation of Ethiopian Cultural Clothing by using Group Technology Coding System." (2016).

[23].Elbenani, Bouazza, and Jacques A. Ferland. "An exact method for solving the manufacturing cell formation problem." International Journal of Production Research 50, no. 15 (2012): 4038-4045.

[24].Martinez, Michel T., Joel Favrel, and Parisa Ghodous. "Product family manufacturing plan generation and classification." Concurrent Engineering 8, no. 1 (2000): 12-23.

[25].Li, Ming-Liang. "The algorithm for integrating all incidence matrices in multi-dimensional group technology." International Journal of Production Economics 86, no. 2 (2003): 121-131.

[26].Djassemi, Manocher. "An efficient CNC programming approach based on group technology." Journal of manufacturing systems 19, no. 3 (2000): 213-217.

[27].Anupama Rajput, Pradip Jamadar, M. Ramachandran, Vishal Fegade, Characterization of Banana Fiber Reinforced with PLA Composites and its Effect on Copper Nano Powder, International Journal of Mechanical and Production Engineering Research and Development, 2018, August, 42-50.

[28].Strusevich, Vitaly A. "Group technology approach to the open shop scheduling problem with batch setup times." Operations Research Letters 26, no. 4 (2000): 181-192. 